Research Article

\title{
Prediction Study of Tunnel Collapse Risk in Advance based on Efficacy Coefficient Method and Geological Forecast
}

\author{
QIU Daohong ${ }^{1, *}$, LI Shucai ${ }^{1}$, XUE Yiguo ${ }^{1}$ and QIN Sheng ${ }^{2}$ \\ ${ }^{1}$ Research Center of Geotechnical and Structural Engineering, Shandong University, Jinan 250061, China \\ ${ }^{2}$ Civil and Environmental Engineering, James Cook University, Townsville, QLD 4811, Australia
}

Received 11 February 2014; Accepted 23 August 2014

\begin{abstract}
Collapse is one of the most common accidents in underground constructions. Risk evaluation is the method of measuring the risk of chamber collapse. To ensure the safety of construction, a risk evaluation model of tunnel collapse based on an efficacy coefficient method and geological prediction was put forward. Based on the comprehensive analysis of collapse factors, five main factors including rock uniaxial compressive strength, surrounding rock integrated coefficient, state of discontinuous structural planes, the angle between tunnel axis and major structural plane and underground water were chosen as the risk evaluation indices of tunnel collapse. The evaluation indices were quantitatively described by using TSP203 system and core-drilling to establish the risk early warning model of tunnel collapse based on the basic principle of the efficacy coefficient method. The model established in this research was applied in the collapse risk recognition of Kiaochow Bay subsea tunnel in Qingdao, China. The results showed that the collapse risk recognition method presents higher prediction accuracy and provided a new idea for the risk prediction of tunnel collapse.
\end{abstract}

Keywords: geological prediction; efficacy coefficient method; collapse; tunnel; TSP203

\section{Introduction}

With the rapid development of underground engineering in China, the engineering geological conditions have been increasingly complicated with many problems. The risk evaluation of tunnel accident has drawn great attentions. In the constructions of the underground engineering, cave-ins occurred frequently due to the complicated geological conditions have lead to huge economic losses and great casualties. To guarantee the safety of tunnel constructions, the risk analysis of tunnel collapse is essential to both theoretical research and engineering application [1], [2], [3].

In the risk evaluation of tunnel collapse, engineering experience analogy method is usually adopted, which predicts the collapse risk along the tunnels by engineering experiences and related information [4]. Some scholars employ comprehensive evaluation methods such as fault tree analysis method and fuzzy evaluation method and so on to comprehensively analyze the collapse-related information to obtain the collapse risks of different sections. In the application of comprehensive evaluation methods, the complexity and variability of the geological conditions in underground engineering are likely to result in some differences in the layer information obtained by the early explorations. It further leads to the differences of collapse risk evaluation indices acquired and the actual layer information. Consequently, the comprehensive evaluation

*E-mail address: qdh2011@126.com

ISSN: 1791-2377 @ 2014 Kavala Institute of Technology. All rights reserved. results of collapse risk are not in agreement with and actual situation [5], [6], [7].

The efficacy coefficient method is a multifactor comprehensive evaluation method. It can convert the assessing indices into evaluation scores measured through efficacy function according to multi-grade standard on basis of multi-objective planning principles. Therefore, the categories of evaluation objects can be determined. Tunnel geological prediction is to predict the surrounding rock and stratum situations in front of the tunnel face by geological and geophysical prospecting means in the excavation of tunnel so that the geological situation based on the early explorations can be further determined. This research put forwards a risk early warning method of tunnel collapse based on efficacy coefficient method and geological prediction and quantitatively describes the collapse risk evaluation indexes by using geological prediction method. To determine the collapse risk level, the authors comprehensively evaluate the evaluation indexes by combining efficacy coefficient method and information entropy weighting method. This method is applied to the collapse risk recognition of Kiaochow Bay subsea tunnel in Qingdao, China and the results are proved to be preferable.

\section{Basic principle and steps of efficacy coefficient method}

Information entropy is a basic index of describing the chaos degree of the system, and it is a variable that determines the information conveyed when events occur from the quantitative angle. There are many factors that affect tunnel 
collapse, so we can regard tunnel collapse as an open chaos system with some rule and better determine the weight value of each evaluation index using information entropy.

Efficacy coefficient method is known as efficacy function method. On basis of multi-objective planning principle, the efficacy coefficient method can convert the indices assessed into the evaluation scores measured through efficacy function, and then calculates the scores of evaluation objects, and determines the object quality according to the scores. The efficacy coefficient method was often used to object comparative, sort, and rarely used to classification. During classification, we usually take the maximum and minimum of a certain index as the satisfaction value and unallowable value, and then delimit the cut-off points of each category based on the principle of equal. This classification method has a problem with subjectivity, and the cut-off point obtained is unscientific. Consequently, in the paper, we have separately calculated the max and min efficacy coefficients using cut-off values of certain levels of each index to determine the cut-off points of the efficacy coefficients so as to make the foundation of the classification more reasonable [8], [9]. The improved main evaluation steps are as follows.

\subsection{Set standard values of each type}

Standard value of a type is the upper and lower limits of indices corresponding to a type. The upper limit value is upper standard value of the type; the lower limit value is the standard value. Assuming that evaluation grade vector is $Y=\left(y_{1}, y_{2}, \cdots, y_{\mathrm{m}}\right)$, grade number is $m$, so the number of type standard values is $m+1$, type standard values denote $k_{j}(j=1,2, \cdots, m+1)$.

\subsection{Determine the standard coefficient of standard value} Standard coefficient is the level factor of standard value corresponding to, which reflects the different levels of standard values, and is used to calculate the scores of the actual values corresponds to the standard values. To the standard values of each category, there are corresponding standard coefficients. The values of standard coefficient can express as values with a range of $0-1$, denote as $\lambda_{j}(j=1,2, \cdots$ $, m+1)$. Formula is as follows:

(1) Efficiency type. The index values greater is better:

$$
\lambda_{i}= \begin{cases}1 & k_{i} \geq x_{\max } \\ \frac{k_{i}-x_{\min }}{x_{\max }-x_{\min }} & x_{\min }<k_{i}<x_{\max } \\ 0 & k_{i} \leq x_{\min }\end{cases}
$$

(2) Cost type. The index values smaller is better:

$$
\lambda_{i}= \begin{cases}1 & k_{i} \leq x_{\min } \\ \frac{x_{\max }-k_{i}}{x_{\max }-x_{\min }} & x_{\min }<k_{i}<x_{\max } \\ 0 & k_{i} \geq x_{\max }\end{cases}
$$

Where $\lambda_{j}$ is the standard coefficient; $k_{i}$ is the standard value; $x_{\max }$ is the maximum index of the evaluation index; $x_{\min }$ is the minimum index.

\subsection{Determine the weights of each index}

Weights reflect the importance of evaluation index to the evaluation results, weights vector is expressed as $W=\left(w_{1}, w_{2}\right.$, $\left.\cdots, w_{n}\right)$, and $\sum_{i=1}^{n} w_{i}=1$. where $w_{i}$ is the weight of each evaluation index.

There are many ways to determine the weights, such as the weighted arithmetic average, Delphi method, AHP method, principal component analysis and so on and so forth. Here we use the entropy weight method. Entropy has been widely used in many fields. In information theory, information is a measurement for the order of a system, and the information entropy is defined as:

$$
\begin{aligned}
& e_{j}=-k \sum_{i=1}^{m} p_{i j} \cdot \ln p_{i j} \quad k=1 / \operatorname{lnm} \\
& p_{i j}=r_{i j} / \sum_{i=1}^{m} r_{i j}
\end{aligned}
$$

Where $r_{i j}$ is the evaluation value of the $i$ th item under the $j$ th index; $e_{j}$ is the chaos degree of the $j$ th evaluation index, so called entropy.

And the entropy weight of index $j$ is:

$$
w_{j}=\left(1-e_{j}\right) / \sum_{j=1}^{n}\left(1-e_{j}\right)
$$

\subsection{Determine the efficacy coefficient of single index}

The efficacy coefficient of single index $e$ consists of two parts; one is the basis score $b$, which can be obtained according to the scores of a index corresponding to the standard value; second is adjusting score $\varepsilon$, which is gotten according to the scores of a index exceeded the standard value [10].

The calculate formula of the basis score is $b_{i}=w_{i} \lambda_{j}$, the calculate formula of adjusting score is:

$\varepsilon_{i}=w_{i}\left(\lambda_{j+1}-\lambda_{j}\right)\left(\frac{x_{i}-k_{j}}{k_{j+1}-k_{j}}\right)$,so efficacy coefficient of single index is:

$$
e_{i}=b_{i}+\varepsilon_{i}=w_{i}\left(\lambda_{j}+\left(\lambda_{j+1}-\lambda_{j}\right)\left(\frac{x_{i}-k_{j}}{k_{j+1}-k_{j}}\right)\right)
$$

Where $k_{j}+1$ is upper standard value, $k_{j}$ is the standard value, $\lambda_{j}+1$ is upper standard coefficient, $\lambda_{j}$ is standard coefficient of the grade, $w_{i}$ is index weights, $x_{i}$ is the index actual value.

\subsection{Calculate the total efficacy coefficient}

The total efficacy coefficient is sum of the efficacy coefficient of each individual index. The formula is:

$$
E=\sum_{i=1}^{n} e_{i}
$$

where $e_{i}$ is the efficacy coefficient of each evaluation index. 
2.6 Determine the total scores of each type and classify evaluation objects

Substitute the standard values of each classification into formula (3), obtain the classification criteria, and then based on the classification criteria, determine the classification of the evaluation object.

\section{Risk evaluation index system of tunnel collapse}

\subsection{Tunnel geological prediction and risk evaluation} index system

By using tunnel geological prediction, the surrounding rock and stratum situations in front of the tunnel face can be predicated in the excavation of tunnel. The main prediction methods consist of geological analysis, geophysical prospecting prediction and drilling analysis. TSP203 system used in wave velocity method is a new advance geological prediction system developed by Amberg Measuring Technique Ltd., Switzerland. It sends signals by conducting the miniature blasting in drilling holes within a certain distance behind the excavation face. The seismic waves caused by blasting spread in a spherical form in the rock mass, and part of them spread ahead of the tunnel. When the seismic waves meet different wave impedance interfaces, some seismic signals are reflected back, and the reflected signals are converted into electric signals and amplified through the sensor. Thus, the related parameters of unfavorable geological bodies can be determined by calculating the reflected signals. The related mechanical parameters are directly obtained from the rock specimen by core drilling in the drilling analysis and the results are proved to be precise.

By analyzing the valid data obtained from geological prediction and collapse factors, five main factors including rock uniaxial compressive strength, surrounding rock integrated coefficient, state of discontinuous structural planes, angle between tunnel axis and major structural plane and underground water are chosen as the risk evaluation indices of tunnel collapse, among which, the later four factors are obtained using TSP203 geological prediction system, and rock uniaxial compressive strength is obtained from core drilling.

\subsection{Determination of evaluation indexes}

(1) Rock uniaxial compressive strength

$R_{c}$ refers to Rock uniaxial compressive strength and directly reflects the hardness degree of rock. The bigger the value of $R_{c}$, the harder the rock; the lower the collapse risk is. Otherwise, the higher the collapse risk is. It is identified by combing horizontal drilling, rock core and indoor tests.

(2) Rock mass integrity coefficient

Rock mass integrity coefficient reflects the integrity of the rock mass, and it is calculated as:

$$
K_{v}=\left(\frac{V_{p}}{V_{s}}\right)^{2}
$$

$V_{p}$ is the longitudinal wave speed of rock and Vs denotes the shear wave speed of rock. Using longitudinal wave speed $V_{p}$ detected by TSP and the shear wave velocity of rock, the rock mass integrity coefficient can be determined.

(3) Angle between the major underground cavities plane and the tunnel axis

There is a close relationship between cavities stability and tunnel axis. In TSP203, reflector location and its angle with the tunnel axis can be acquired by calculating reflection time and speeds of the seismic waves.

(4) The state of discontinuity structural plane

The state of discontinuity structural plane presents the roughness and filling of controlling structural plane, and indicates as $N$ in this paper. When structural plane is weak, the reflected waves show negative reflection. The worse the structural plane properties, the stronger the reflection. Thus, the relative strength of $P$ wave negative reflection was applied in the quantization of this index. The reflection value is donated as the state of discontinuity structural plane. The larger the reflection value, the worse the structural plane properties; while the smaller the reflection value, the better the structural plane properties.

According to a large number of TSP forecasting experiences, this research proposed the following quantitative methods. Structural plane was rough and not continuous, and results interpretation of the $\mathrm{P}$ wave showed no significant reflection(0 0.2); when micro-rough, structural plane opening degree was less than $1 \mathrm{~mm}$, results interpretation showed slight $\mathrm{P}$ wave reflection(0.2 0.4); while micro-rough, structure plane opening degree was less than $1 \mathrm{~mm}$, rock severely weathered and results interpretation presented apparent $\mathrm{P}$ wave reflection(0.4 0.6); slip plane or silted plane was less than $5 \mathrm{~mm}$, results interpretation indicated strong $\mathrm{P}$ wave reflection(0.6 0.8); when soft mud silted was greater than $5 \mathrm{~mm}$, results interpretation showed strong $\mathrm{P}$ wave reflection too and the whole rock mass longitudinal and shear velocity decreased, also the level of velocity changed frequently, $(0.8 \sim 1.0)$ [11], [12].

(5) Underground water

Underground water is an important factor affecting the stability of surrounding rock. The influences of water mainly include dissolving the soluble cement in the rock and structural plane, leading to the softer rock, and decrease of the strength [13]. Given that the development state of underground water in early exploration stage is uncertain, the TSP geological prediction method is used to detect it. The development state of underground water determined by TSP is a qualitative index, which can be quantified according to table 1 . GW represents the state of underground water in the research.

Table 1. Grade division of underground water influence

\begin{tabular}{|c|c|c|}
\hline Level & Specific description & Values \\
\hline I & $\begin{array}{l}\text { Groundwater is greatly developed with serious water } \\
\text { problem. TSP migration diagrams interpretation shows } \mathrm{S} \\
\text { wave reflection is significantly stronger than } \mathrm{P} \text { wave. S } \\
\text { wave reflection strip is wide with good extension. Beside, } \\
\text { increasing rate of } V_{p} / V_{s} \text { is more than } 50 \% \text {. }\end{array}$ & $0.8-1.0$ \\
\hline II & $\begin{array}{l}\text { Groundwater is more developed; TSP migration diagrams } \\
\text { interpretation shows } \mathrm{S} \text { wave reflection is significantly } \\
\text { stronger than } \mathrm{P} \text { wave. Poisson's ratio suddenly increases. } \\
\text { Beside, increasing rate of } V_{p} / V_{s} \text { is more than } 40 \% \text {. }\end{array}$ & $0.6-0.8$ \\
\hline III & $\begin{array}{l}\text { Groundwater is developed, fissure water is found. TSP } \\
\text { migration diagrams interpretation shows } \mathrm{S} \text { wave reflection } \\
\text { is obviously stronger than } \mathrm{P} \text { wave. Beside, increasing rate } \\
\text { of } V_{p} / V_{s} \text { is more than } 30 \% \text {. }\end{array}$ & $0.4-0.6$ \\
\hline IV & $\begin{array}{l}\text { Groundwater is less developed, the chamber is moist. TSP } \\
\text { migration diagrams interpretation shows the } \mathrm{S} \text { wave } \\
\text { reflection is stronger than } \mathrm{P} \text { wave. Beside, increasing rate } \\
\text { of } V_{p} / V_{s} \text { is more than } 15 \% \text {. }\end{array}$ & $0.2-0.4$ \\
\hline $\mathrm{V}$ & $\begin{array}{l}\text { None developed ground water, the chamber is dry. TSP } \\
\text { migration diagrams interpretation shows no water features. } \\
\text { Beside, increasing rate of } V_{p} / V_{s} \text { is more than } 5 \% \text {. }\end{array}$ & $0-0.2$ \\
\hline
\end{tabular}




\section{Engineering application}

4.1 Engineering situation and grading standards of collapse risk

Kiaochow bay subsea tunnel in Qingdao is the second subsea Tunnel with large cross-section in China. It is an important channel that connects the main urban center of Qingdao with assistant cities. It connects South Xuejia island in the south and Tuan Island in the north, and crosses the mouth of Jiaozhou Bay area downwardly. The average depth in this sea area is about $7 \mathrm{~m}$, and the maximum depth is $65 \mathrm{~m}$, while the maximum depth of bay mouth is $42 \mathrm{~m}$. The tunnel serves both as urban road and highway. It has six lanes in both directions and the vehicle speed is set to $80 \mathrm{~km} / \mathrm{h}$. There are two three-lane tunnels with distance of 55 $\mathrm{m}$ in axis and a service tunnel, as shown in figure 1.

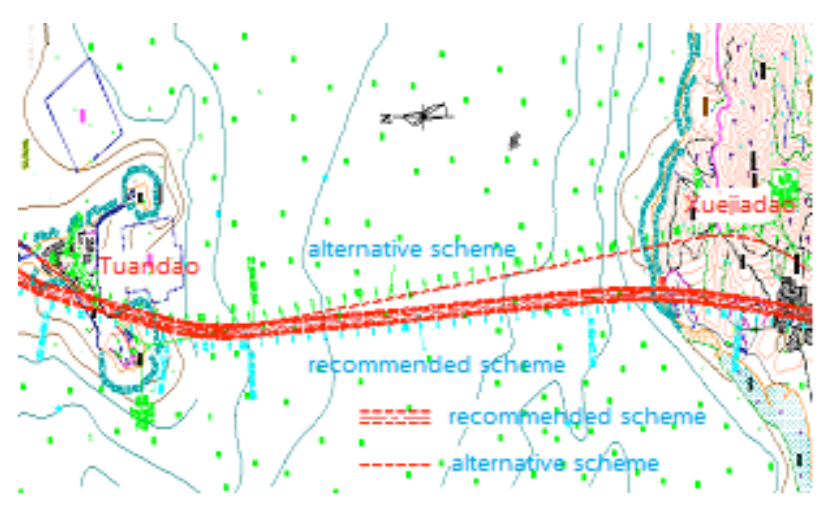

Fig.1. Layout plan of Qingdao Kiaochow bay subsea tunnel

This tunnel is $7,120 \mathrm{~m}$ in length, among which, the main tunnel is $6,170 \mathrm{~m}$ in length; while, the seabed is $3,950 \mathrm{~m}$ approximately. There are two three-lane tunnels and a service tunnel. The sections in the main tunnels are elliptical with $10.363 \mathrm{~m}$ in net height and 14.426 in width. The vertical section in the tunnel presents the slope in the form of "V" with a maximum longitudinal slope of less than $4 \%$. The maximum longitudinal slope is $3.9 \%$ in the design. The buried depth in sea area usually ranges from 20 to $30 \mathrm{~m}$. The New Austrian Tunneling Method was used throughout the construction of the tunnel.

According to the related research results, the tunnel collapse risks are divided into 5 levels, respectively: the extremely high risk, high risk, medium risk, low risk, and minor risk. The corresponding level of risks are level I, level
II, level III, level IV and level V. The specific standards for classifying tunnel collapse risk level are shown in Table 2, and grading standards are illustrated in table 3.

Table 2. Classifying standards of collapse risks

\begin{tabular}{|c|c|c|c|c|c|}
\hline Level & \multicolumn{5}{|c|}{ Acceptance criteria } \\
\hline $\begin{array}{r}\text { Ex } \\
\text { re } \\
\mathrm{s}\end{array}$ & \multicolumn{5}{|c|}{$\begin{array}{l}\text { Extremely high risk is not acceptable. The greatest importance } \\
\text { requires to be attached and take measure to avoid and transfer } \\
\text { such risk. It is need to be at least decreased to level IV after } \\
\text { occurrence. }\end{array}$} \\
\hline $\mathrm{H}$ & \multicolumn{5}{|c|}{$\begin{array}{l}\text { High risk is partially acceptable. Its occurrence usually cause } \\
\text { serious consequence to the whole project, it is need to be } \\
\text { reduced to level III at least and strengthen the monitoring and } \\
\text { establish early-warning measures. }\end{array}$} \\
\hline III & \multicolumn{5}{|c|}{$\begin{array}{l}\text { Medium risk is acceptable, but need to pay attention to; it } \\
\text { should be considered in design; in construction, a detailed } \\
\text { management plan is required. }\end{array}$} \\
\hline IV & \multicolumn{5}{|c|}{$\begin{array}{l}\text { The risk is low and allowable. The risk measures are not } \\
\text { required, routine management is needed with attention. }\end{array}$} \\
\hline $\mathrm{V}$ & \multicolumn{5}{|c|}{ Risk is too low to be ignored, no risk measures } \\
\hline \multirow{2}{*}{\multicolumn{6}{|c|}{ ble 3. Indices and criteria for collapse risk assessment }} \\
\hline & & & & & \\
\hline$R_{c}(\mathrm{Mpa})$ & $5-10$ & $10-20$ & $20-40$ & $40-80$ & $80-120$ \\
\hline$K_{v}$ & $0-0.2$ & $0.2-0.35$ & $0.35-0.5$ & $0.5-0.75$ & $0.75-1$ \\
\hline$\theta\left(^{\circ}\right)$ & $0-10$ & $10-30$ & $30-70$ & $70-80$ & $80-90$ \\
\hline$N$ & $0.8-1.0$ & $0.6-0.8$ & $0.4-0.6$ & $0.2-0.4$ & $0-0.2$ \\
\hline$G W$ & $0.8-1.0$ & $0.6-0.8$ & $0.4-0.6$ & $0.2-0.4$ & $0-0.2$ \\
\hline
\end{tabular}

\subsection{Determination of standard coefficients of standard} value with varied levels

In the index evaluation system of collapse risk assessment, the development state of structural plane and underground water are classified as efficiency indicators: the larger their value, the poorer the stability of rock, the bigger the collapse risks, and the assessment grade of is lower. Rc, $\mathrm{Kv}$ and $\theta$ are cost indicators. The smaller the values, the poor stability of rock, the greater collapse risk. In the Table 3, the limits of the classification standards of each index are chosen as the standard value of each type. The standard coefficients of each type are determined using the method in Section 2.2, as shown in Table 4.

Table 4. Standard value and standard coefficient of each classification

\begin{tabular}{|c|c|c|c|c|c|c|c|c|c|c|}
\hline \multirow{2}{*}{$\begin{array}{c}\text { Collapse risk } \\
\text { level }\end{array}$} & \multicolumn{2}{|c|}{$R c($ Мра) } & \multicolumn{2}{|c|}{$K v$} & \multicolumn{2}{|c|}{$\theta\left(^{\circ}\right)$} & \multicolumn{2}{|r|}{$N$} & \multicolumn{2}{|c|}{$G \boldsymbol{W}$} \\
\hline & $\begin{array}{l}\text { standard } \\
\text { value }\end{array}$ & $\begin{array}{c}\text { standard } \\
\text { coefficients }\end{array}$ & $\begin{array}{l}\text { standard } \\
\text { value }\end{array}$ & $\begin{array}{c}\text { standard } \\
\text { coefficients }\end{array}$ & $\begin{array}{l}\text { standard } \\
\text { value }\end{array}$ & $\begin{array}{c}\text { standard } \\
\text { coefficients }\end{array}$ & $\begin{array}{l}\text { standard } \\
\text { value }\end{array}$ & $\begin{array}{c}\text { standard } \\
\text { coefficients }\end{array}$ & $\begin{array}{l}\text { standard } \\
\text { value }\end{array}$ & $\begin{array}{c}\text { standard } \\
\text { coefficients }\end{array}$ \\
\hline $\mathrm{I}$ & 10 & 0.96 & 0.2 & 0.8 & 10 & 0.89 & 0.8 & 0.8 & 0.8 & 0.8 \\
\hline II & 20 & 0.87 & 0.35 & 0.65 & 30 & 0.67 & 0.6 & 0.6 & 0.6 & 0.6 \\
\hline III & 40 & 0.70 & 0.5 & 0.5 & 70 & 0.22 & 0.4 & 0.4 & 0.4 & 0.4 \\
\hline IV & 80 & 0.35 & 0.75 & 0.25 & 80 & 0.11 & 0.2 & 0.2 & 0.2 & 0.2 \\
\hline $\mathrm{V}$ & 120 & 0 & 1 & 0 & 90 & 0 & 0 & 0 & 0 & 0 \\
\hline
\end{tabular}

\subsection{Engineering application}

To test the applicability of the method, the model was applied to advance geological forecast on a high-risk tunnel section by combining coring drilling and TSP203. The stake number of the tunnel face detected using TSP was FK4+375. $\mathrm{F}$ refers to service tunnel and $\mathrm{K}$ represents kilometers. Horizontal coring drilling was started from the tunnel face FK4 +375. The tunnel rock in this section was very fragmented with varied lithology. Besides, there were many fault fracture zones and fault fracture affected zone .The lithology consists of mainly lava tuff breccia and granite.

To obtain results including the the tunnel section P-wave depth migration (Figure2), SH-wave depth migration (Figure 3 ), rock physical properties Figure (Figure 4) and the forecast results 2D view(Figure 5), collected data on the TSP203 was processed to using TSPwin software. In results interpretation, the rocks was classified mainly based on $\mathrm{P}$ 
wave information; meanwhile SV wave was applied to explain geological phenomena. Therefore, the predication area was proved to be in the part of $45 \mathrm{~m}$ in front of tunnel face. It included four predicting tunnel sections: FK $4+375$ $\sim+363, \mathrm{FK} 4+363 \sim+347, \mathrm{FK} 4+347 \sim+334$ and FK4+334 $\sim+320$. The TSPwin was used to obtain $\mathrm{P}$ wave depth migration (Figure 2) and $\mathrm{SH}$ wave depth migration (Figure 3 ). Figure 2 and Figure 3 present the reflections of structural plane in front of tunnel; while, Figure 4 shows the physical properties of rock. Figure 5 is the $2-d$ view results of predication, among which, the blue denotes fractured rock and the red is integral rock; the reflection line in blue indicates the reflection of weak structural plane, the reflection line in red represents the reflection of hard structural plane.

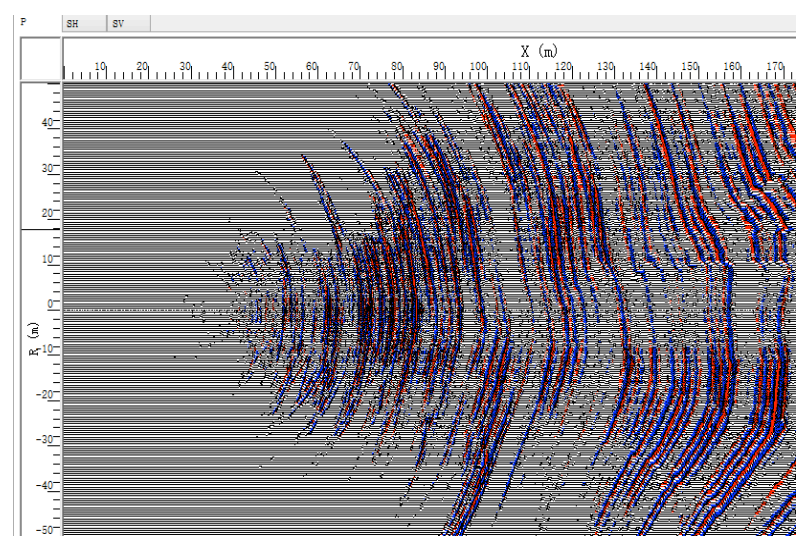

Fig. 2. $P$ wave depth migration

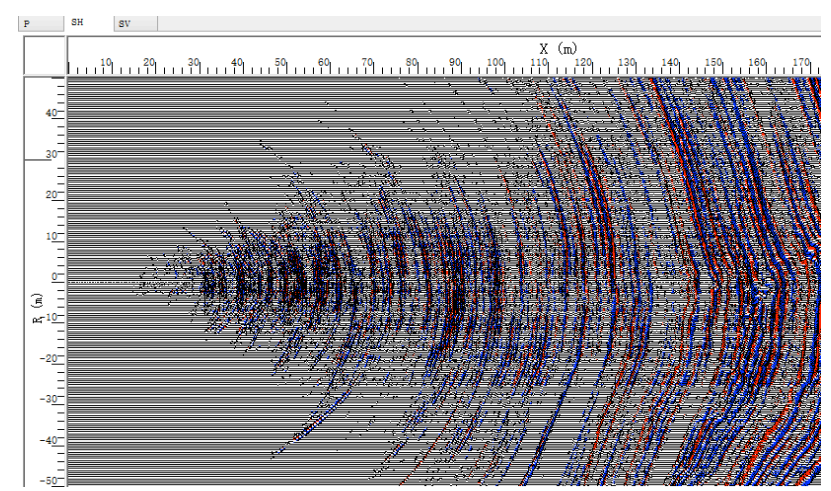

Fig. 3. SH wave depth migration

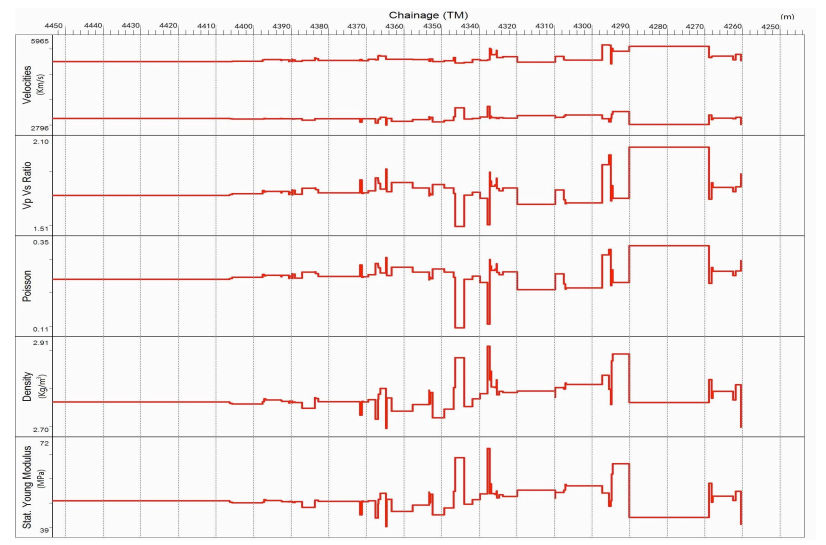

Fig. 4. Rock physical properties

The evaluation indexes of each tunnel section were determined using the method proposed in section 3.2 in this paper, as shown in table 5. Afterwards, the determined evaluation indexes were handled dimensionlessly to eliminate the size gap among the index values. Then, according to equations (1) and (2) from entropy theory, the weight of each index can be acquired, as shown in table 6. $e_{j}$ is confusion degree; while $d_{j}$ is significance and $w_{j}$ denotes the weight of index.

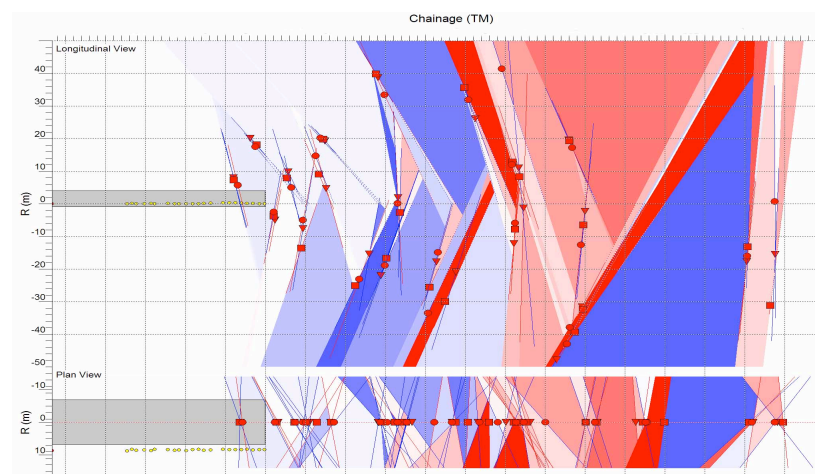

Fig. 5. 2D pictures of prediction results

Table 5. Physico-mechanical parameters of rocks

\begin{tabular}{cccccc}
\hline Mileage & $\boldsymbol{R}_{\boldsymbol{c}}$ (Mpa) & $\boldsymbol{K}_{\boldsymbol{v}}$ & $\boldsymbol{\theta}\left(^{\circ}\right)$ & $\boldsymbol{N}$ & $\boldsymbol{G W}$ \\
\hline 4+375 +363 & 51 & 0.39 & 32 & 0.59 & 0.31 \\
4+363 +347 & 22 & 0.24 & 15 & 0.77 & 0.38 \\
4+347 +334 & 8 & 0.11 & 8 & 0.95 & 0.51 \\
4+334 +320 & 47 & 0.37 & 41 & 0.43 & 0.32 \\
\hline
\end{tabular}

Table 6. Confusion degree, significance and weighting coefficient of the indexes

\begin{tabular}{cccccc}
\hline Index & $\boldsymbol{R}_{\boldsymbol{c}}$ & $\boldsymbol{K}_{\boldsymbol{v}}$ & $\boldsymbol{\theta}$ & $\boldsymbol{N}$ & $\boldsymbol{G} \boldsymbol{W}$ \\
\hline$e_{j}$ & 0.873 & 0.933 & 0.885 & 0.970 & 0.985 \\
$d_{j}$ & 0.127 & 0.067 & 0.115 & 0.030 & 0.015 \\
$w_{j}$ & 0.36 & 0.19 & 0.33 & 0.08 & 0.04 \\
\hline
\end{tabular}

By using the weight of each index, the standard value of each category and standard coefficients combined with the efficacy coefficient calculation formula (3), the value range of total efficacy coefficient of each collapse risk level can be obtained. Taking risk level I for an example, from Table 4 we can see that the standard value of the lower limit of level I surrounding rock is $(120,1,90,0,0)$, and the standard coefficient is $(0,0,0,0,0)$; the standard value of the previous grade is $(80,0.75,80,0.2,0.2)$, and the standard coefficient of the previous grade is $(0.35,0.25,0.11,0.2,0.2)$. When the actual value is $(120,1,90,0,0)$, the total efficiency coefficient of lower limit of the risk level I is 1 ; the total efficiency coefficient of upper limit of risk level I is 0.8873 ; the value range of total efficiency coefficient for risk level $\mathrm{I}$ is $0.8873 \sim 1$. Similarly, the value range of other levels can also be obtained as: level II is 0.7298 0.8873; level III is $0.4676 \sim 0.7298$; level IV is $0.2338 \sim 0.4676$ and level $\mathrm{V}$ is $0 \sim 0.2338$.

Based on equation (3) and the index value of each evaluation tunnel section in table (5), the collapse risk of each evaluation tunnel section can be calculated (see table 7). Tunnel section 1, for example, the value of rock compressive strength is $51 \mathrm{MPa}$, and it can be categorized into risk level IV based on Table 3. Then according to Table 4 , we can see the standard value of this grade is 80 and the standard coefficient is 0.35 ; the standard value of previous grade is 40 , the standard coefficient of previous grade is 0.70 , and the weight is 0.39 . According to formula (3), the efficiency coefficient of rock compressive strength is calculated as: 


$$
e_{1}=0.36\left[0.35+(0.75-0.35) \frac{51-80}{40-80}\right]=0.21735
$$

The value of rock integrality coefficient is 0.39 . According to Table 3, it can be classified into level III. Then according to Table 4 , the standard value and standard coefficient of this grade both are 0.5 ; the standard value of previous grade is 0.35 , the standard coefficient is 0.65 and its weight is 0.19 . Using formula (3), the efficiency coefficient of rock integrality coefficient is obtained as:

$$
e_{2}=0.19\left[0.5+(0.65-0.5) \frac{0.39-0.5}{0.35-0.5}\right]=0.1159
$$

The angle of tunnel axis and layered rock is 32.In Table 3 , it can be categorized into level III. Then according to Table 4, the standard value of this grade is 70 , and the standard coefficient is 0.22 ; the standard value of previous grade is 30 , the standard coefficient is 0.67 , and its weight is 0.33 . On the basis of formula (3), the efficiency coefficient of the angle of tunnel axis and layered rock is:

$$
e_{3}=0.33\left[0.22+(0.67-0.22) \frac{32-70}{30-70}\right]=0.213675
$$

Considering the value of the state of structural plane (0.59), based on Table 3, it can be categorized into level III. Then according to Table 4, the standard value and standard coefficient of this grade both are 0.4 ; the standard value of previous grade is 0.6 , the standard coefficient is 0.6 and its weight is 0.08 . According to formula (3), the efficiency coefficient of the state of structural plane is:

$$
e_{4}=0.08\left[0.4+(0.6-0.4) \frac{0.59-0.4}{0.6-0.4}\right]=0.0472
$$

The GW is 0.31 , and judging from Table 3, it can be categorized into level III. Then according to Table 4 , it is known that the standard value and standard coefficient of this grade both are 0.2 ; the standard value and standard coefficient of previous grade are both 0.4 and its weight is 0.04 . Using formula (3), the efficiency coefficient of GW is obtained as:

$$
e_{5}=0.04\left[0.20+(0.40-0.20) \frac{0.31-0.2}{0.4-0.2}\right]=0.0124
$$

According to formula (4), the total efficiency coefficient is calculated:

$$
E=\sum_{i=1}^{5} e_{i}=0.606525
$$

\begin{tabular}{|c|c|c|c|c|c|c|c|c|c|c|c|c|c|}
\hline \multirow[b]{2}{*}{ Tunnel } & \multirow{2}{*}{$\begin{array}{c}R_{c} \\
\text { (Mpa) }\end{array}$} & \multirow[b]{2}{*}{$\boldsymbol{K}_{v}$} & \multirow[b]{2}{*}{$\begin{array}{c}\theta \\
\left({ }^{\circ}\right)\end{array}$} & \multirow[b]{2}{*}{$N$} & \multirow[b]{2}{*}{$\boldsymbol{G W}$} & \multicolumn{5}{|c|}{ Efficiency coefficient } & \multirow{2}{*}{$\begin{array}{c}\text { Total } \\
\text { efficiency } \\
\text { coefficient }\end{array}$} & \multirow{2}{*}{$\begin{array}{c}\text { Calculated } \\
\text { level }\end{array}$} & \multirow[b]{2}{*}{ Actual level } \\
\hline & & & & & & $\boldsymbol{R}_{c}$ & $K_{v}$ & $\theta$ & $N$ & $G W$ & & & \\
\hline No.1 & 51 & 0.39 & 32 & 0.59 & 0.31 & 0.217 & 0.115 & 0.213 & 0.047 & 0.012 & 0.6065 & III & II $\sim$ III \\
\hline No. 2 & 22 & 0.24 & 15 & 0.77 & 0.38 & 0.307 & 0.144 & 0.275 & 0.061 & 0.015 & 0.8038 & II & II \\
\hline No.3 & 8 & 0.11 & 8 & 0.95 & 0.51 & 0.351 & 0.169 & 0.300 & 0.076 & 0.020 & 0.9178 & I & II \\
\hline No.4 & 47 & 0.37 & 41 & 0.43 & 0.32 & 0.229 & 0.119 & 0.180 & 0.034 & 0.012 & 0.5771 & III & II \\
\hline
\end{tabular}

The total efficiency coefficient of tunnel 1 can be categorized into level $\mathrm{III}(0.4676 \sim 0.7298)$, so the risk of tunnel 1 is medium risk.

Table 7. The evaluation result of tunnel collapse risk

The evaluation results of calculated level and actual one are compared and analyzed in Table 7 . In Table 7 , given there is no special classification standard regarding tunnel collapse risk, in the determination of actual risk level of tunnel collapse, the invited experts referred some tunnel collapse examples which had occurred in water conservancy, hydropower or highway, and railway industry, then scored the tunnel. Afterwards, the average scores were calculated to determine the collapse risks of each tunnel section. Table 7 shows that the evaluation results of tunnel collapse risk in tunnel section 2 using the model is basically in agreement with the expert evaluation; there are slight deviations between evaluation results using the model and actual level in tunnel sections 1,3 , and 4 ,the results are generally consistent. Owing to the evaluation method is conducted by machine, evaluation method has some shortfalls in the value range and construction of evaluation index system. Those shortfalls may lead to some deviations, generally, the method can be a favorable trying.

\section{Conclusion}

(1) This paper presents a method of predicting the tunnel collapse risk in front of the tunnel face based on advance geological prediction detection results using efficacy coefficient method. Engineering applications show that the method is practical and feasible. It provides a new idea for collapse risk assessment of mountain tunnel.

(2) In this paper, the efficacy coefficient method is applied to evaluate the collapse risk of mountain tunnel. Judging from the actual excavation, this method is beneficial for identifying tunnel collapse risk in advance. It is able to avoid the uncertainty in the application of empirical method. However, this method is just an evaluation and analysis methods, due to many factors affecting the risk level of collapse in mountain tunnel, the authors will further improve the evaluation index system in practical application, and adopt a more scientific approach to determine the weight of each index to improve the accuracy of collapse risk identification.

(3) On the basis of advance geological prediction detecting precision, the method can improve the classification accuracy only by enhancing detecting precision and the accuracy of interpretation of the data. Meanwhile, the classification result obtained, as a machine classification results, can provide a reference for the actual collapse risk assessment in mountain tunnel. The method has high precision in identification of the typical tunnel collapse. In the case of the collapse ranging between the two 
categories, it is required to be determined by on-site experience of engineering geology personnel.

\section{Acknowledgements}

This work was financially supported by National Natural Science Foundation of China (51309144), Independent Innovation Foundation of Shandong University (2012TS063), Shandong Provincial Natural Science Foundation (ZR2013EEQ024).

\section{References}

[1]. CHEN Jiejin, ZHOU Feng, YANG Junsheng, et al. "Fuzzy analytic hierarchy process for risk evaluation of collapse during construction of mountain tunnel", Rock and Soil Mechanics 30(12), 2009, pp. 3622-3626.

[2]. AN Yonglin, PENG Limin, WU Bo, etc. "Comprehensive extension assessment on tunnel collapse risk", Journal of Central South University(Science and Technology) 42( 2), 2011,pp. 514520.

[3]. Li, R.T.H., Chung, H.S.H., Chan, T.K.M., "An active modulation technique for single-phase grid-connected CSI", IEEE Transactions on Power Electronics 22 (4), 2007, pp. 1373-1382.

[4]. LI Shucai, SHI Shaoshuai, LI Liping, etc. "Attribute Recognition Model and Its Application of Mountain Tunnel Collapse Risk Assessment",Journal Of Basic Science And Engineering 21(1), 2013, pp.147-158.

[5]. CHEN Long, HUANG Hongwei. "Risk analysis of rocktunnel engineering”, Chinese Journal of Rock Mechanics and Engineering 24(1), 2005, pp. 110-115.

[6]. Alan N. Beard. "Tunnel safety, risk assessment and decisionmaking", Tunnelling and Underground Space Technology (25) 2010,pp. 91-94.

[7]. LI Shucai, XUE Yiguo,ZHANG Qingsong,etc. "Key technology study comprehensive prediction and early warning of geological hazards during tunnel construction in high-risk karst areas", Chinese Journal of Rock Mechanics and Engineering 27(7), 2008, pp.1297-1307.
[8]. MENG Fanqi, LI Guangjie, WANG Qingbing, et al. "Research on early warning of debris flow based on efficacy coefficient method", Rock and Soil Mechanics 33(3), 2012, pp. 835-840.

[9]. QIU Daohong, XUE Yiguo, SU Maoxin, et al. "Study on surrounding rock stability based on the efficacy coefficient method and rough set", Journal of Shandong University (Engineering Sciences) 41(5), 2011, pp. 92-96.

[10]. WANG Yingchao, SHANG Yuequan, SUN Hongyue, et al. "Research and application of rockburst intensity prediction model based on entropy coefficient and ideal point method", Journal of China Coal Society 35(2), 2010, pp. 218-221.

[11]. QIU Daohong, LI Shucai, ZHANG Lewen, et al. "Prediction of surrounding rock classification in advance based on TSP203 system and GA-SVM", Chinese Journal of Rock Mechanics and Engineering supplement (1), 2010, pp. 3221-3226.

[12]. XU Zhenhao, LI Shucai, ZHANG Qingsong, et al. "Reflection characteristic of seismic wave in TSP advance geological prediction", Chinese Journal of Underground Space and Engineering 4(4), 2008, pp.640-644.

[13]. LI Shucai, LI Shuchen, ZHANG Qingsong, et al. "Forecast of karst-fractured groundwater and defective geological conditions", Chinese Journal of Rock Mechanics and Engineering 26(2), 2007, pp.217-225. 